\title{
Multivariate real-time assessment of droughts via copula-based multi-site Hazard Trajectories and Fans
}

\author{
G. Salvadori ${ }^{\mathrm{a}, *}$, C. De Michele ${ }^{\mathrm{b}}$ \\ a Dipartimento di Matematica e Fisica, Università del Salento, Provinciale Lecce-Arnesano, P.O. Box 193, I-73100 Lecce, Italy \\ ${ }^{\mathrm{b}}$ Department of Civil and Environmental Engineering, Politecnico di Milano, Piazza Leonardo da Vinci 32, I-20133 Milano, Italy
}

\section{S U M M A R Y}

Droughts, like floods, represent the most dangerous, and costly, water cycle expressions, with huge impacts on society and built environment. Droughts are events occurring over a certain region, lasting several weeks or months, and involving multiple variables: thus, a multivariate, multi-site, approach is most appropriate for their statistical characterization. In this methodological work, hydrological droughts are considered, and a multivariate approach is proposed, by regarding as relevant variables the duration and the average intensity. A multivariate, multi-site, frequency analysis is presented, based on the Theory of Copulas and the joint Survival Kendall's Return Periods, by investigating the historical drought epi-sodes occurred at five main river sections of the Po river (Northern Italy), the most important Italian basin. The tool of Dynamic Return Period is used, and the new concepts of Hazard Trajectories and Fans are introduced, in order to provide useful indications for a valuable multi-site real-time assessment of droughts.

\section{Introduction}

According to Beran and Rodier (1985), "Droughts are generally viewed as a sustained and regionally extensive occurrence of below average natural water availability, either in the form of precipitation, river runoff, or groundwater". In literature, several works have pointed out as a main obstacle to the drought investigation the lack of a precise definition (see, among others, Yevjevich, 1967; Wilhite and Glantz, 1987; Demuth and Külls, 1997).

Palmer (1965) defined droughts as a meteorological phenomenon characterized by a prolonged and abnormal moisture deficiency. Wilhite and Glantz (1987) and McKee et al. (1993) summarized drought definitions as a natural phenomenon that originates from a deficit in precipitation, which results in water shortage for some activities or group. In a recent review, Mishra and Singh (2010) have defined droughts as a temporary phenomenon characterized by the reduction in the amount of precipitation received over an extended period of time, such as a season or a year.

Dracup et al. (1980a), reviewing several definitions of droughts, underlined that droughts are a wide concept covering different fields of study. Droughts have been categorized in four different

\footnotetext{
* Corresponding author. Tel.: +39 083229 7584; fax: +39 0832297594.

E-mail addresses: gianfausto.salvadori@unisalento.it (G. Salvadori),

carlo.demichele@polimi.it (C. De Michele)
}

classes (Dracup et al., 1980a; Beran and Rodier, 1985; Wilhite and Glantz, 1987):

hydrological: relatively to below normal flow and depleted reservoir storage;

meteorological: relatively to below normal precipitation;

agricultural: if the soil moisture is not sufficient to support crop growth;

socio-economical: if the low water supply affects socio-economic activities.

These definitions describe only qualitatively a drought. Operational definitions, which consider main drought features like onset, termination, duration, severity, and intensity, are necessary to quantitatively address the problem (Wilhite and Glantz, 1987).

Gumbel (1963) defined the hydrologic drought as the smallest annual value of the mean daily discharge, and used the third asymptotic distribution of the smallest value (i.e., EV III type law) to derive the return period of droughts occurred in Muskegon (Michigan) and French-Broad (North Carolina) rivers. Similarly Gannon (1964) investigated the hydrologic droughts in Michigan, during the period May-October, defining these as the smallest value of the mean discharge over periods of $1,7,15$, and 30 consecutive days, and used Extreme Value distributions. A criticism to these approaches is that hydrological droughts are described only 
through the maximum water deficit, without considering the length of the drought and the total water deficit.

Yevjevich (1967) proposed a threshold approach, also called run method, to identify hydrologic droughts. Thus, a drought (negative run) is characterized by a duration, the interval during which the discharge is below, or equal to, a fixed threshold, and a severity, defined as the cumulative volume deficit below the given threshold. The ratio between severity and duration is the average intensity of drought. Conversely, the period during which the discharge is above the fixed threshold is a positive run. The run method has been widely applied to yearly and daily data. Examples considering the former time scale include Sen (1977), Dracup et al. (1980b), Clausen and Pearson (1995), and also Clausen and Pearson (1998), where the threshold has been fixed equal to the long-term mean annual flow, or the $75 \%$ of it. Examples considering daily data include, among others, Zelenhasić and Salvai (1987), Tallaksen et al. (1997), Demuth and Külls (1997), Demuth and Heinrich (1997), Kjeldsen et al. (2000), Engeland et al. (2004), Byzedi and Saghafian (2009), and Byzedi (2010). However, the application of run method to sub-yearly time scales (e.g., daily ones) requires a particular attention to the possible presence of mutually "dependent" droughts, i.e. to the fact that a prolonged dry period may be interrupted by shorter ones where the flow exceeds the threshold level, and therefore a long drought turns out to be divided into a number of shorter ones.

Zelenhasić and Salvai (1987) studied the number, severity, duration, time of occurrence, largest duration, and largest severity of drought events of Sava river at Sr. Mitroviea, and Tisa river at Senta (both in ex-Yugoslavia), using the run method with daily data and, as thresholds, the 95-, 90-, 80-, 70-, and 60-percentile of the flowduration curve. They found that the 95- and 90-percentiles are more statistically correct to identify droughts, since the events belong to the region of low extremes. The maximum annual duration and severity were modeled using an exponential distribution. Zelenhasić and Salvai (1987) have modified the run method to account for the temporal dependence of consecutive drought periods. They introduced two additional conditions: (i) two consecutive droughts, separated by a short interval (inter-event time) during which the flow is slightly above the threshold, have to be considered as just one drought, with duration and severity equal to the sum of the two events duration and severity, respectively and (ii) all droughts having a severity less than $0.5 \%$ of maximum value are discharged.

Tallaksen et al. (1997) applied the run method to daily data of two catchments in Denmark, using as thresholds the 50-, 70- and 90- percentile of the flow-duration curve. Three different procedures were considered to pool together mutually dependent droughts: (i) an inter-event time and volume criterion, (ii) a moving average procedure, and (iii) a method based on the sequent peak algorithm. The first criterion, similar to the one proposed by Zelenhasić and Salvai (1987), states that if the inter-event time between two successive droughts is less than, or equal to, a critical duration, and the ratio between the inter-event excess volume and the preceding deficit volume is less than a critical value, then the two droughts have to be pooled into a single drought, with duration equal to the sum of the durations of the two events and the inter-event time, while the volume is given by the sum of the two events volumes minus the inter-event excess volume. The moving average procedure has to be applied directly to the flow time series to smooth it and remove the minor peaks; then, the run method can be applied to the smoothed time series. The sequent peak algorithm, used for the design purposes of reservoirs, states that a drought is identified as a continuous period of storage depletion; thus, two droughts are dependent if at the beginning of the second one the reservoir has not yet recovered from the first one. The drought volume is the maximum storage depletion within the event, and the duration is given by the difference in time between the maximum depletion instant and the starting time of the drought. The same methodologies have been applied by Fleig et al. (2006) to sixteen daily flow series collected at different sites of the world, with thresholds equal to 70- and 90-percentiles of the flow-duration curve.

Demuth and Külls (1997) used the run method for analyzing daily data of 27 stations in the south of Germany, using as a threshold the 90-percentile of the flow-duration curve. To avoid dependence problem of successive droughts, a termination criterion at $10 \%$ was used: a positive volume of a maximum $10 \%$ of the foregoing drought volume is allowed before terminating an event. Demuth and Külls (1997) extracted the maximum annual duration and severity, and for each of these estimated the parameters of LogNormal, Generalized Extreme Value, Pearson III, and Generalized Pareto distribution using L-moments and Partial Probability Weighted Moments. Demuth and Heinrich (1997) investigated the drought duration in 111 stations located in south Germany, using as a threshold the 90-percentile of the flow-duration curve, and a termination criterion at $10 \%$.

Kjeldsen et al. (2000) studied droughts occurrences in ten Zimbabwean rivers (some ephemeral and others perennial) using daily data. In this case, the threshold was chosen to vary monthly, due to the strong seasonality of the region climate, and defined as the 75percentile of the monthly flow-duration curve. Note that, for ephemeral rivers, the expected flow during the dry season is zero, which corresponds to a truncation level equal to zero. In the case of a drought starting in the rainy season, the begin of the dry season involves an increase in the duration, but not in the severity. The drought can also go over the dry season and foregoing in the next rainy season until the daily stream flow is below the threshold. Perennial rivers yield no problem regarding the drought definition, being the thresholds different from zero in all the months. Possible mutually dependent droughts were identified using the sequent peak algorithm methodology (Tallaksen et al., 1997). To estimate the return period of drought severity and duration, a two-component exponential distribution was used for both variables.

Engeland et al. (2004) applied the run method to daily Norwegian data, using as a threshold the 70-percentile of the flow-duration curve, and a 10-days moving average procedure to cope with dependent droughts. A Generalized Extreme Value and a Generalized Pareto distribution were fitted to the maximum annual severity.

Recently, Byzedi and Saghafian (2009) and Byzedi (2010) used the run method, with a truncation level at the $70 \%$ of the daily discharge, and the inter-event time criterion to pool together dependent droughts, to investigate forty-four hydrometric stations in South-Western Iran. A frequency analysis of the annual maximum drought severity and duration was performed.

In literature, until 2000, the drought frequency analysis has been addressed principally under a univariate framework: viz., by calculating the probability distribution of drought duration and drought severity, and considering these variables as independent. However, droughts are multi-dimensional random phenomena characterized by duration, severity and intensity variables, each dependent on one another. Thus, a multivariate probabilistic framework is advisable for a proper description of droughts.

The introduction of Copulas in hydrology (De Michele and Salvadori, 2003) has greatly facilitated the multivariate modeling of droughts: see, among others, Shiau (2006), Serinaldi et al. (2009), Shiau and Modarres (2009), Kao and Govindaraju (2010), Wong et al. (2010), Song and Singh (2010, 2011), Mirabbasi et al. (2012), Ganguli and Reddy (2012), Reddy and Ganguli (2012), Chen et al. (2013), De Michele et al. (2013), Ganguli and Reddy (2014), and also Mishra and Singh (2011) for a review. In the above mentioned works, with the exceptions of Kao and Govindaraju 
(2010), Song and Singh (2010), Song and Kang (2011), and De Michele et al. (2013), the drought considered is of a meteorological kind, and the relevant variable is the standardized precipitation index. Instead, Kao and Govindaraju (2010) investigated both meteorological and hydrological droughts via standardized indices, introducing a joint deficit index to provide a probability-based description of the drought at different time scales. In addition, Song and Singh (2010) addressed hydrological droughts via a tri-variate analysis of duration, severity, and inter-arrival time, as identified by means of a threshold on the flow discharge. Further-more, Song and Kang (2011) considered the pair-copula construc-tion method to build high-dimensional dependence structures, and carried out a trivariate analysis of the variables duration, severity, and severity peak, as identified by means of a threshold on the flow discharge. Lastly, De Michele et al. (2013) presented a multivariate frequency analysis of hydrological droughts where droughts are intended as episodes during which the flow discharge is below a given threshold: in this work, the new concept/tool of Dynamic Return Period was introduced to assess the dangerousness of the drought along with its temporal evolution, and provide a practical tool to water resource managers to quantify dynamically (i.e., day-by-day) the "rarity" of a drought event during its occurrence.

In this paper, we shall follow the multivariate survival approach outlined in Salvadori et al. (2013) and De Michele et al. (2013). The overall behavior of the major Italian river basin will be investigated, by considering some relevant historical drought episodes occurred at five main river sections, thus carrying out a multi-site analysis on the same main-stream: as we shall see, this may provide useful information for the proper management of the water resource. In addition, the new concepts of Hazard Trajectories and Fans will be introduced, which may supply suitable indications for the real-time assessment of droughts. As a difference with other works available in literature, which essentially only provide descriptive models of the drought dynamics, here the target is also to introduce new methodological tools for extracting further valuable information from the available data, and to show their usefulness for water managers.

The paper is organized as follows. In Section 2, the data base and the case study are presented. In Section 3, the theoretical framework adopted is briefly illustrated, and all the relevant notions used in the paper are introduced: these include the Survival Kendall's Return Period, the Dynamic Return Period, and the Hazard Trajectories and Fans. In Section 4, the analysis of the data base is shown, and the main results are illustrated and discussed. Finally, suitable conclusions are drawn in Section 5.

\section{The data base}

The Po is the largest Italian river basin, covering an area of about $74,000 \mathrm{~km}^{2}$, crossing the Pianura Padana from Western Alps to the Adriatic sea, with a main river length of about $650 \mathrm{~km}-$ see Fig. 1 . The basin is an economic important area, with a population of more than 16 Millions of habitants, producing about $40 \%$ of the national gross domestic product. Water uses involve several strategic activities: viz., agriculture, livestock, inland navigation, and industry. As a consequence, drought may cause serious detriments.

In this work we use daily discharge data (in $\mathrm{m}^{3} / \mathrm{s}$ ) collected at five different river sections located along the main stream chan-nel -see Fig. 1: namely, from West to East, Piacenza, Cremona, Boretto, Borgoforte and Pontelagoscuro. The observations are avail-able since 1924 at Piacenza and Borgoforte, since 1972 at Cremona, since 1943 at Boretto (but missing the years 1945 and 1946), and since 1923 at Pontelagoscuro; all the time series terminate in 2007. Further details about the data base and the morphological features of the sub-basins can be found in Turco et al. (2013).

Hereinafter we shall investigate hydrologic droughts, i.e. periods of time during which the discharges are smaller than prescribed thresholds-see Table 1: these values are those indicated by the Control Room (hereinafter, $C R$ ) in a recent report (AA. VV., 2011). In particular, the standard thresholds Q275, Q300, and Q355 (labeled by the CR as, respectively, "Alert", "Alarm", and "Emergency") will be used: these correspond to the discharge values exceeded, respectively, 275, 300, and 355 days per year. Clearly, approaches different from the one presented here are possible, as thoroughly discussed in Section 1.

As in De Michele et al. (2013), two main variables are used to characterize each drought episode: namely, the average Intensity

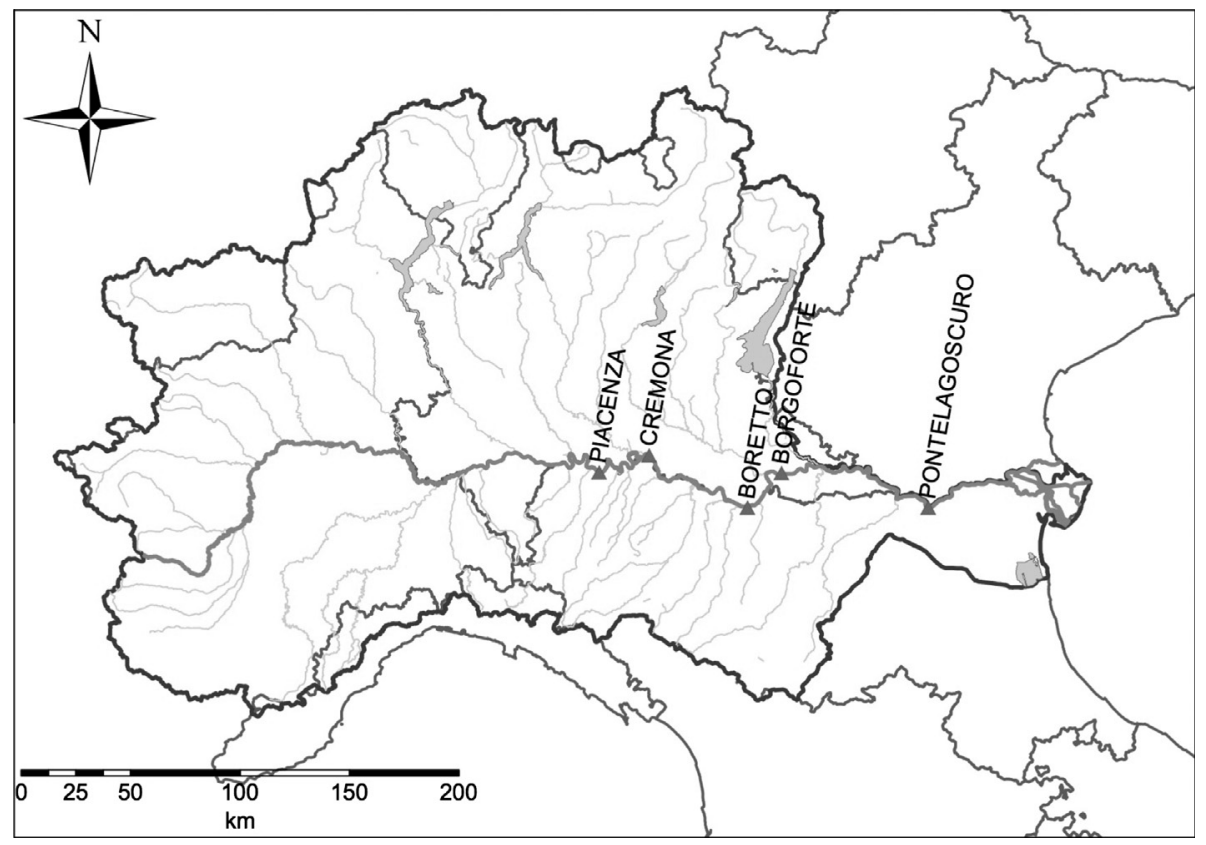

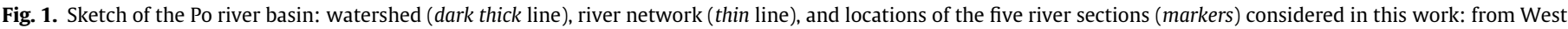
to East, Piacenza, Cremona, Boretto, Borgoforte, and Pontelagoscuro. 
Table 1

Values of the three discharge thresholds Q275, Q300, and Q355 (in $\mathrm{m}^{3} / \mathrm{s}$ ) considered in this work, for all the five river sections of interest. The "\#" rows report the number of available drought episodes extracted from the data base, while the " $\tau$ " rows show the values of the Kendall's rank correlation coefficient $\tau$-see text

\begin{tabular}{llll}
\hline Section & Q275 & Q300 & Q355 \\
\hline Piacenza & 536 & 490 & 376 \\
$\#$ & 327 & 284 & 112 \\
$\tau$ & 0.41 & 0.40 & 0.36 \\
Cremona & 651 & 591 & 445 \\
$\#$ & 129 & 107 & 42 \\
$\tau$ & 0.46 & 0.41 & 0.56 \\
Boretto & 687 & 616 & 451 \\
$\#$ & 227 & 197 & 81 \\
$\tau$ & 0.49 & 0.43 & 0.37 \\
Borgoforte & 809 & 728 & 524 \\
$\#$ & 328 & 267 & 99 \\
$\tau$ & 0.47 & 0.41 & 0.45 \\
Pontelagoscuro & 913 & 824 & 593 \\
$\#$ & 335 & 276 & 106 \\
$\tau$ & 0.48 & 0.45 & 0.43 \\
\hline
\end{tabular}

I (i.e., the average of all the daily differences between the threshold and the actual discharge, in $\mathrm{m}^{3} / \mathrm{s}$ ), and the Duration $D$ (in days). In addition, a minimum inter-event time of 3 days, and a minimum drought duration of 5 days, is used in order to identify the events of interest, and to circumvent possible dependencies between successive droughts: therefore, in the following we shall consider the bivariate drought observations as independent and identically distributed. The number of episodes extracted is reported in Table 1: as expected, the sample size decreases by lowering the threshold. For a discussion concerning the use of other variables see De Michele et al. (2013, Section 2). Briefly, from a practical point of view, complete drought episodes are characterized by a duration and an average intensity. Similarly, the daily status of an evolving drought is characterized by a duration (i.e., the number of days since the beginning of the episode) and a (running) average intensity: clearly, each day of an evolving drought could be the last one. In turn, the treatment and analyses are perfectly consistent.

Table 2

Survey of the extreme features of the available data-see text. The legend is as follows: "Date" is the initial date of the drought episode (dd.mm.yy); " ${ }^{*}$ " is the maximum observed average intensity (in $\mathrm{m}^{3} / \mathrm{s}$ ), and " $D_{*}$ " is the corresponding observed duration (in days); " $D^{* \prime}$ is the maximum observed duration (in days), and " $I_{*}$ " is the corresponding observed average intensity (in $\mathrm{m}^{3} / \mathrm{s}$ ). The durations in parentheses indicate the actual number of days during which the discharge was below the corresponding Q-threshold.

\begin{tabular}{lllllll}
\hline Section & Date & $I^{*}$ & $D_{*}$ & Date & $I_{*}$ & $D^{*}$ \\
\hline & Q275 & & & & & \\
Piacenza & 07.04 .65 & 270 & $58(57)$ & 21.08 .89 & 149.87 & 230 \\
Cremona & 24.05 .06 & 291 & $114(112)$ & 21.08 .89 & 177 & $241(236)$ \\
Boretto & 31.05 .05 & 331 & 90 & 07.09 .89 & 197 & $213(207)$ \\
Borgoforte & 08.06 .45 & 411 & 63 & 08.09 .89 & 224 & $212(210)$ \\
Pontelagoscuro & 08.06 .45 & 512 & 64 & 03.01 .44 & 369 & $191(184)$ \\
& $Q 300$ & & & & & \\
Piacenza & 10.04 .65 & 242 & 53 & 08.09 .89 & 115 & $212(208)$ \\
Cremona & 25.05 .06 & 236 & $113(110)$ & 07.09 .89 & 131 & $213(208)$ \\
Boretto & 26.05 .06 & 321 & 84 & 20.05 .03 & 203 & $165(160)$ \\
Borgoforte & 31.05 .05 & 340 & 90 & 01.10 .89 & 167 & $189(179)$ \\
Pontelagoscuro & 08.06 .45 & 432 & 64 & 20.05 .03 & 296 & $166(162)$ \\
& $Q 355$ & & & & & \\
Piacenza & 06.04 .38 & 180 & 43 & 09.07 .90 & 91 & $98(97)$ \\
Cremona & 01.06 .06 & 165 & 77 & 01.06 .06 & 165 & 77 \\
Boretto & 02.06 .06 & 178 & 76 & 12.06 .03 & 110 & $88(84)$ \\
Borgoforte & 02.06 .06 & 219 & 77 & 13.07 .62 & 175 & 92 \\
Pontelagoscuro & 03.06 .06 & 302 & 77 & 13.07 .62 & 138 & 93
\end{tabular}

As an illustration, in Table 2 we present a survey of some extreme drought episodes recorded in the data base. Note that the maximum intensity never occurs in the same event showing the maximum duration (with the only exception of CremonaQ355 in 2006): apparently, this may indicate that, in order to properly rank the threatening of a drought, both the two variables $I$ and $D$ need to be jointly taken into account, as we shall outline below.

\section{Methods}

The analysis of the drought data presented in the previous section will be carried out by using the same approach, both univariate and multivariate, adopted in Salvadori et al. (2013), De Michele et al. (2013), and Salvadori et al. (2014): we shall make reference to these papers for all the mathematical details, assumptions, and justifications. For the sake of clarity and completeness, below we briefly present the main concepts and notions of interest.

In order to construct suitable statistical models for all the five river sections and the three thresholds, we shall consider the same univariate and multivariate distributions described and used in De Michele et al. (2013): these are reported in Table 3. Furthermore, the (corrected) Akaike Information Criterion (AIC) (Burnham and Anderson, 2002; Claeskens and Hjort, 2008) will be used as a model selection strategy. In addition, the Kolmogorov-Smirnov (KS) Goodness-of-Fit test, returning approximate $p$-values calcu-lated by using Monte Carlo procedures (Davison and Hinkley, 1997), will endorse the appropriateness of the chosen univariate distributions, while the multivariate Goodness-of-Fit tests sug-gested in Genest et al. (2009, Appendix A) will validate the suitabil-ity of the selected copulas. Finally, the Randomization Techniques outlined in De Michele et al. (2013, Section 3) and Salvadori et al.(2014, Section 3 ) will be used to cope with the presence of repeated values (Ties) in the data base-for a discussion and a graphical illustration, see e.g. Figs. 1 and 2 in the first cited paper. In particular, the median AIC's and $p$-values, over all the $N_{R}=100$ randomizations performed here, will be used as reference values for selecting and testing the statistical models of interest.

\subsection{The multivariate Return Period}

In the following, the notion of multivariate Return Period (hereinafter, $R P$ ) will play a fundamental role. In particular, let $\mathbf{x}=(I, D)$ be a generic drought episode or state. Here we adopt the Survival Kendall's RP $\kappa_{\mathbf{x}}^{-}$(hereinafter, SKRP), defined in Salvadori et al.(2013) and De Michele et al. (2013, Eqs. (1) and (2)), as a tool for the multivariate frequency analysis of the droughts. As emphasized in Gräler et al. (2013), the SKRP provides a consistent and suitable framework for investigating and parametrizing the joint occurrences of hydrological variables (see, later, Figs. 2-4).

Table 3

List of the six univariate distributions and twelve bivariate survival copulas fitted on the available data-see text. The "GEV" and "GP" labels denote, respectively, the Generalized Extreme Value and the Generalized Pareto univariate distributions. The "Clayton", "Gumbel", and "Frank" labels denote the corresponding families of Archimedean 2-copulas (Nelsen, 2006; Salvadori et al., 2007); the labels "Mix[AB]" denote a convex mixture $\mathbf{C}$ of the two families $\mathbf{A}$ and $\mathbf{B}$ indicated (i.e., $\mathbf{C}=\lambda \mathbf{A}+(1-\lambda) \mathbf{B}$, with $\lambda \in[0,1])$; the labels "X[AB]" denote the Khoudraji-Liebscher extraparametrization C of the two families A and B indicated (Durante and Salvadori, 2010; Salvadori and De Michele, 2010).

\begin{tabular}{lll}
\hline Univariate & Survival copulas & \\
\hline Exponential & Clayton & XClaytonGumbel \\
Gamma & Frank & XClaytonFrank \\
GEV & Gumbel & XGumbelFrank \\
GP & MixClaytonGumbel & XClaytonClayton \\
LogNormal & MixClaytonFrank & XGumbelGumbel \\
Weibull & MixGumbelFrank & XFrankFrank \\
\hline
\end{tabular}



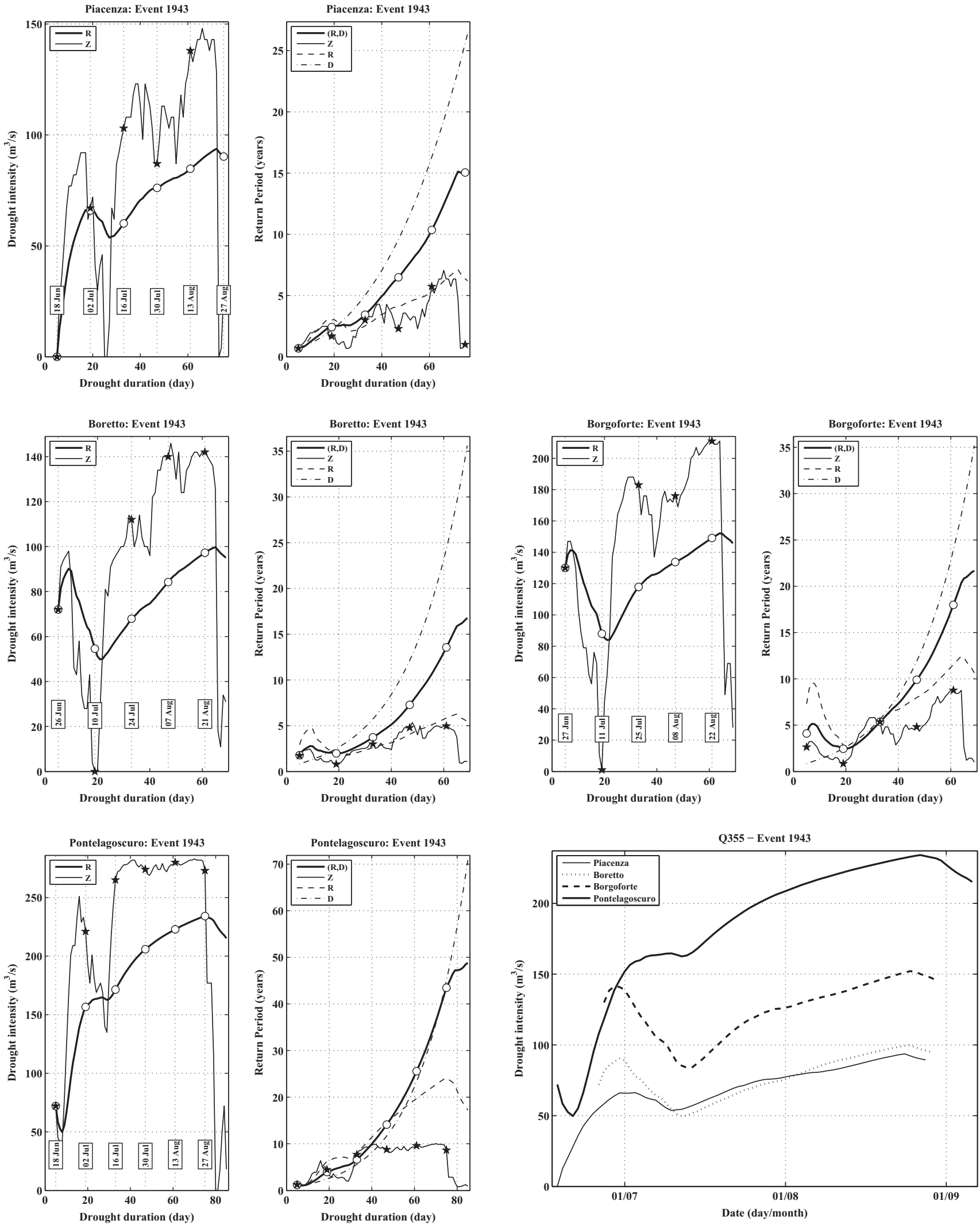

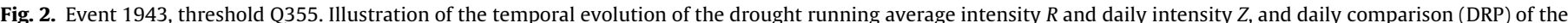

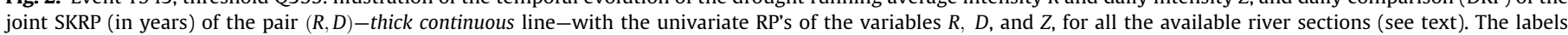

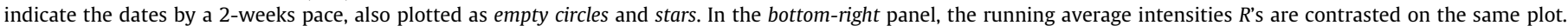



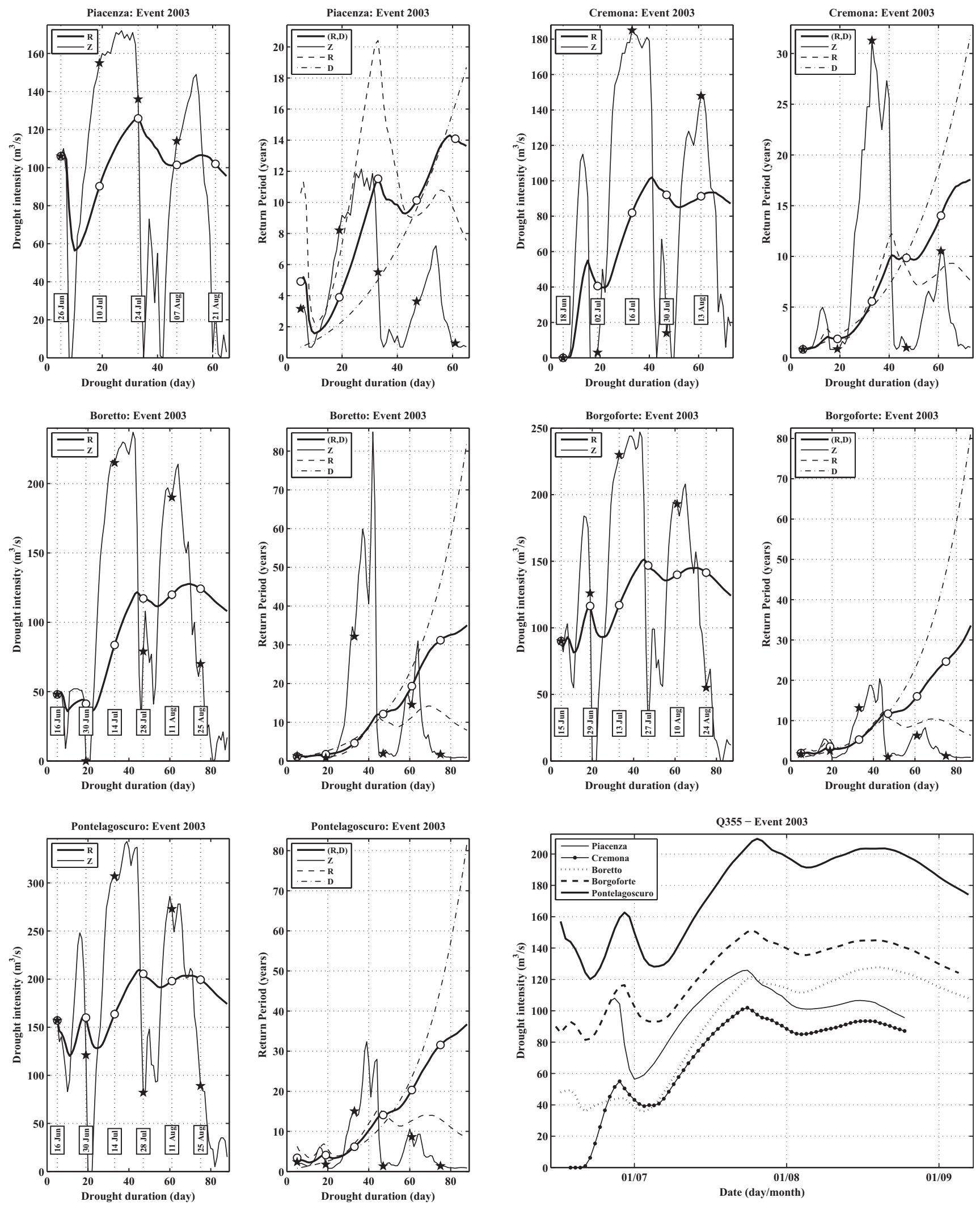

Fig. 3. Event 2003, threshold Q355. Same as Fig. 2.

\subsection{The Dynamic Return Period}

The Dynamic Return Period (hereinafter, $D R P$ ) procedure, first outlined in De Michele et al. (2013, Section 6), consists in the cal- culation of the sequence of SKRP's $\bar{\kappa}_{1}, \bar{\kappa}_{2}, \ldots$ associated with the temporal evolution of the drought states $\left(I_{1}, 1\right),\left(I_{2}, 2\right), \ldots$ observed in successive days since the beginning of the episode. Generally speaking, since the notion of Return Period represents an index 

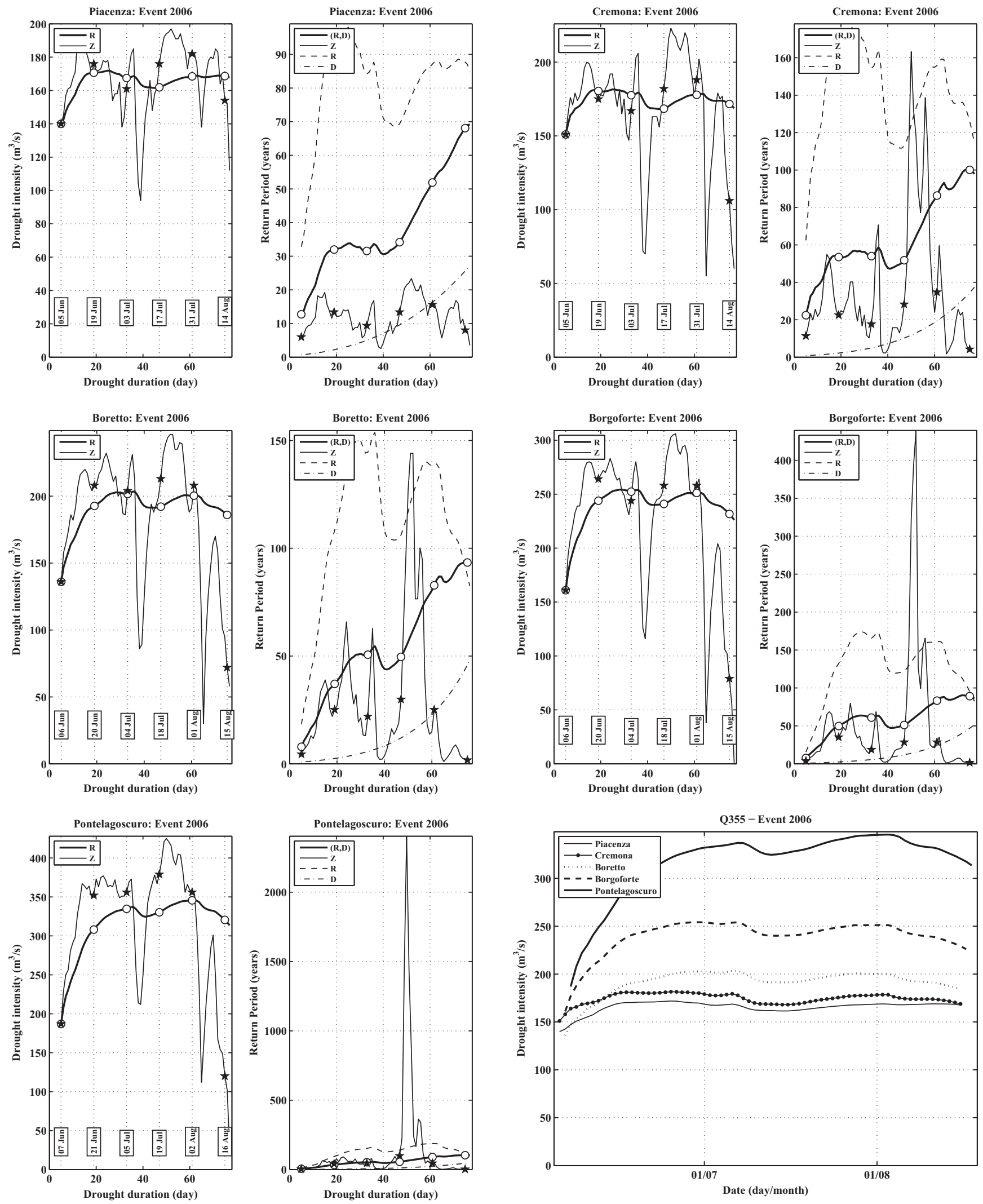

Fig. 4. Event 2006, threshold Q355. Same as Fig. 2.

of dangerousness of the phenomenon under investigation, the DRP procedure applied to the drought episodes considered in this work will provide a daily evaluation of their threatening (see, later, Section 4, and Figs. 2-7).

\subsection{The Hazard Trajectory}

A new tool, denominated "Hazard Trajectory" (hereinafter, $H T$ ), is introduced in this work (see, later, Section 4.2, and Figs. 5-7). A 

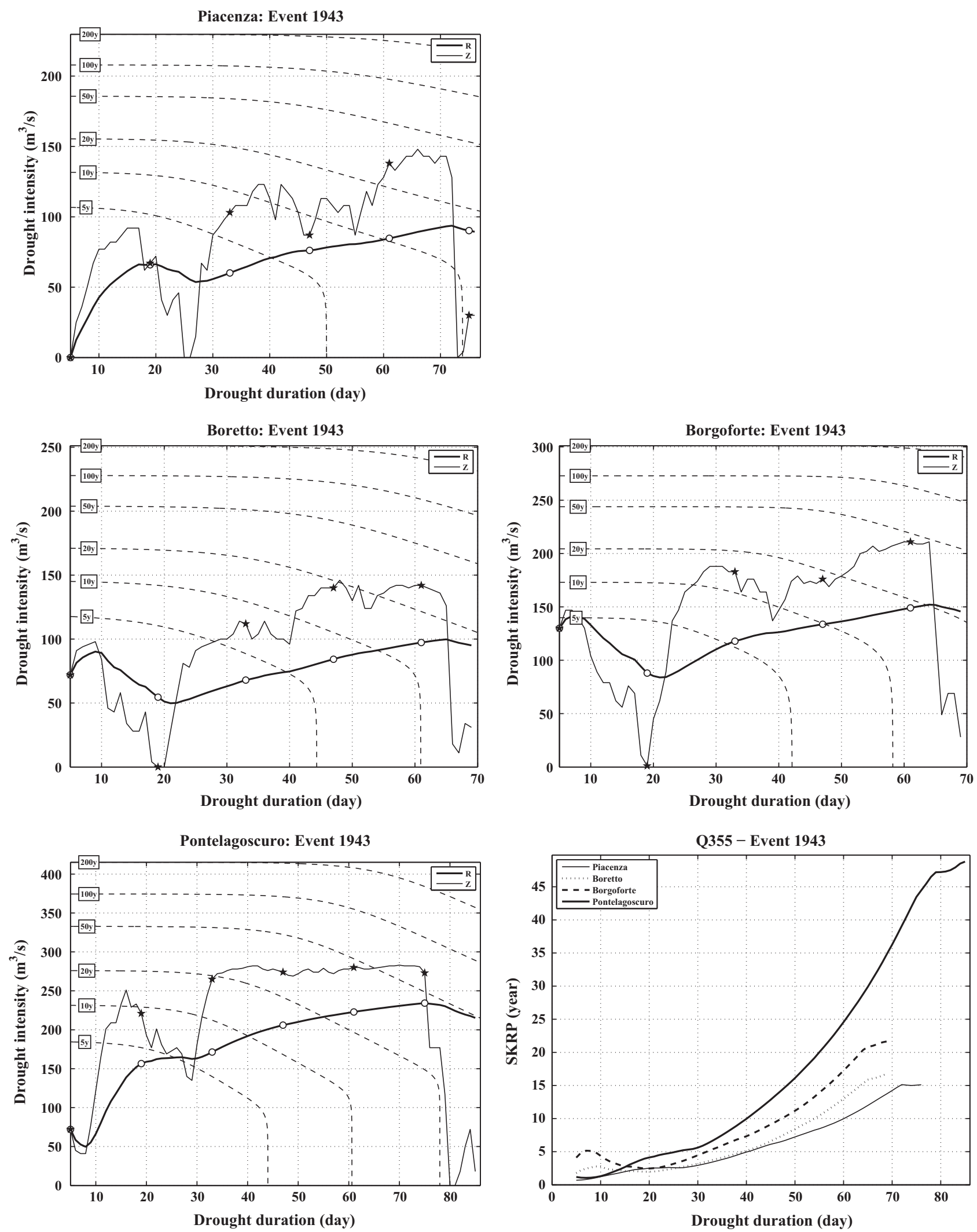

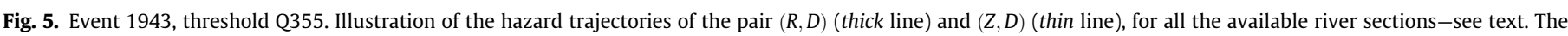

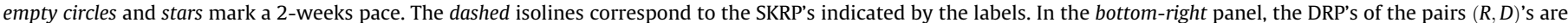
contrasted on the same plot.

HT is simply the sequence of drought states $\left(I_{1}, 1\right),\left(I_{2}, 2\right), \ldots$ drawn in the Duration-Intensity plane, where suitable isolines corresponding to given Return Periods are plotted. Such an integrated chart can help visualize the temporal evolution of the DRP's quickly, offering an easy tool to monitor in real-time the threatening of a drought episode. 

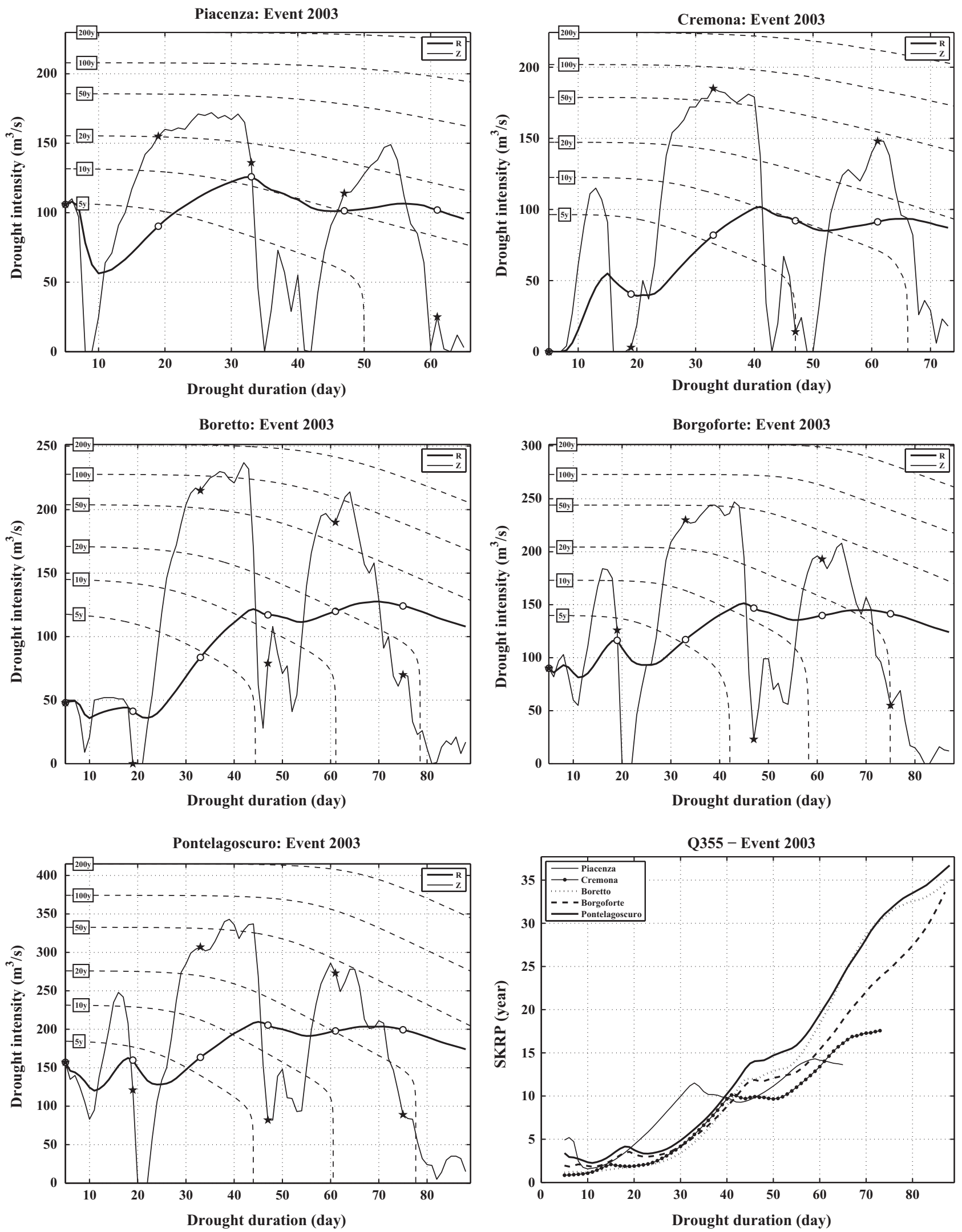

Fig. 6. Event 2003, threshold Q355. Same as Fig. 5. 

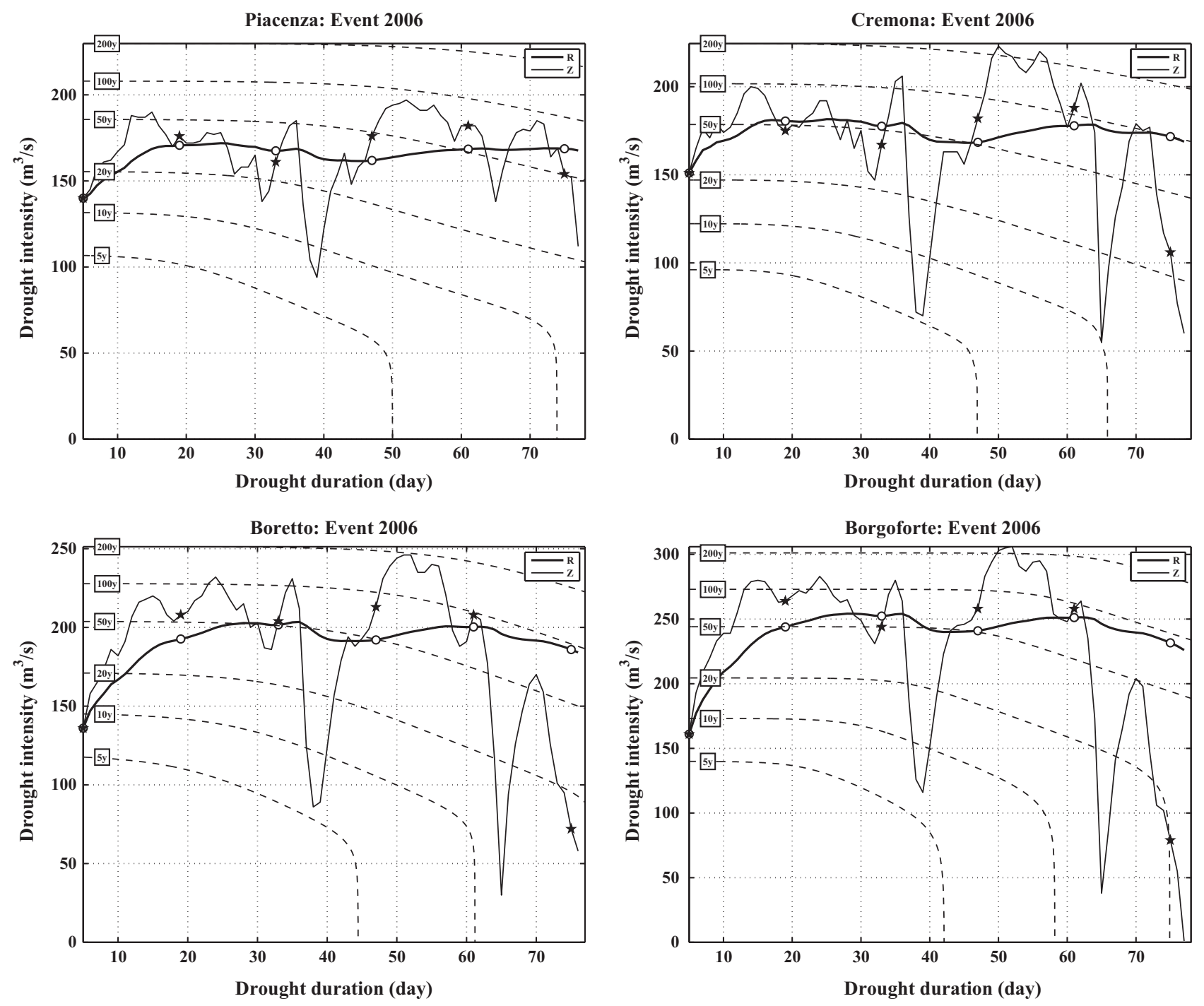

Pontelagoscuro: Event 2006
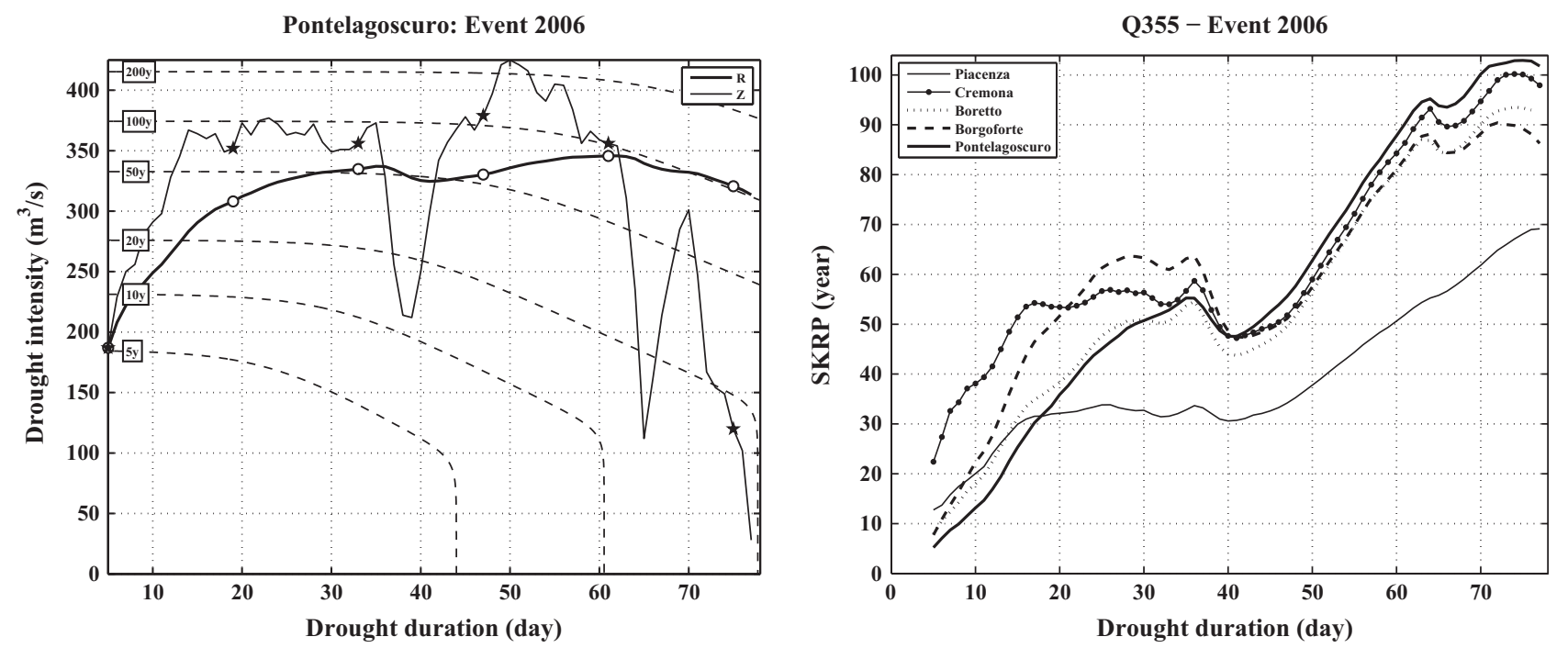

Fig. 7. Event 2006, threshold Q355. Same as Fig. 5.

\subsection{The Hazard Fan}

An interesting novel approach concerning the risk assessment in engineering practice is outlined in the Directive 2007/60/EC of The European Parliament and of The Council (The European
Parliament and The Council, 2007): this document deals with the assessment and the management of flood risks, but the strategies proposed are paradigmatic, and can be adopted in all areas of environmental engineering, including drought assessment. Actually, the term "drought" can be substituted for "flood" in the cited 


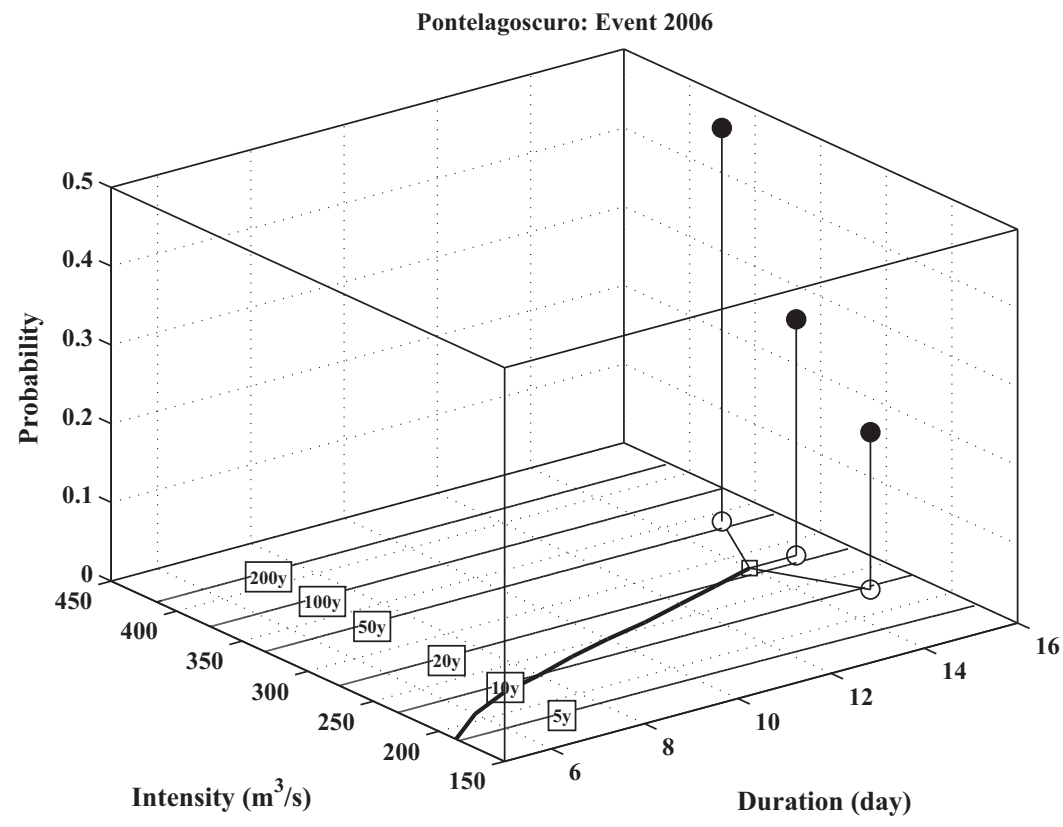

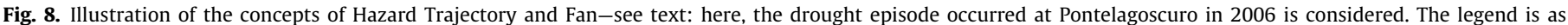

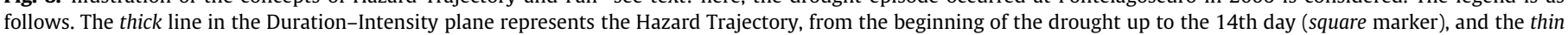

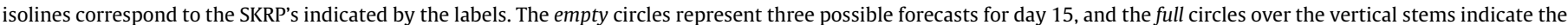
estimated probability of each scenario: this plot corresponds to the Hazard Fan.

Directive. In particular, the Directive states that (The European Parliament and The Council (2007, p. 30, Chapter III, Article 6.3) the flood risk management should require the implementation of suitable "flood hazard maps covering the geographical areas which could be flooded according to the following scenarios: (a) floods with a low probability, or extreme event scenarios; (b) floods with a medium probability (likely return period $\geqslant 100$ years); (c) floods with a high probability, where appropriate." Moreover, a multivariate approach is recommended (The European Parliament and The Council (2007, p. 31, Chapter III, Article 6.4), since it is suggested to consider, for each flood scenario, the following quantities: "(a) the flood extent; (b) water depths or water level, as appropriate; (c) where appropriate, the flow velocity or the relevant water flow". In turn, the scope of the Directive is twofold. On the one hand, the EU framework requires the specification of suitable stochastic models for the flood events that are per se multivariate (viz., they involve a number of non-independent variables for the character-ization of a flood). On the other hand, relevant flood scenarios of interest are indicated, each associated with prescribed probability levels (or Return Periods).

Thus, following the European Parliament recommendations, a further new tool, denominated "Hazard Fan" (hereinafter, $H F$ ), is introduced in this work (see, later, Section 4.3, and Fig. 8). The idea is to combine the information about the actual state of a drought (and the corresponding SKRP, measuring its dangerousness) with possible forecasts of the future intensity, typically on a daily basis (as is traditional for the Po basin): the target is to provide a previsional tool, able to supply useful real-time (statistical) information about possible near-future drought scenarios. The forecast of the next-day(s) intensity may be based on weather-meteo models, rainfall-runoff algorithms, Control Room planning, and so on. Practically, given the present drought state, several next-day states can be predicted, each with an associated probability. Then, by plotting such future states in the Duration-Intensity plane, a "fan" of possible scenarios can be visualized, each characterized by a well defined SKRP: in turn, the (statistical) evolution of the drought threatening can easily be monitored, and real-time decisions can be taken by the water managers.

\section{Data analysis}

As a preliminary step, according to the survival approach adopted in this work, the multivariate statistical modeling of the droughts requires to estimate the joint survival function of the variables $I$ and $D$. In turn, as thoroughly explained in De Michele et al. (2013, Section 5), suitable univariate marginals and survival copulas must first be fitted to these two variables. Note that $I$ and $D$ are definitely concordant (Nelsen, 2006; Salvadori et al., 2007), i.e. positively dependent: actually, the estimates of the Ken-

dall's rank correlation coefficient $\tau$ reported in Table 1, for all the river sections and the thresholds considered in this work, are all statistically significantly positive, viz. the independence hypothesis is always rejected (the same result is obtained by using the Spearman's independence test).

Tables 4 and 5 show, respectively, the univariate distributions and the bivariate survival dependence structures selected for all the five river sections and the three thresholds of interest. The results deserve a due discussion.

As already mentioned above, the choice of the selected distributions was carried out via the (corrected) AIC, and their appropriateness was checked via suitable Goodness-of-Fit tests. At first glance, no regular distributional patterns are present in Tables 4 and 5: however, this is more apparent than real. In fact, a check and a comparison of all the estimated AIC's (a total of 180 values in the univariate case -5 river sections $\times 3$ thresholds $\times 2$ variables $\times 6$ laws-and a total of 180 values in the bivariate case- 5 river sections $\times 3$ thresholds $\times 12$ copulas) show that, in almost all cases, the computed AIC's are close to one another. Thus, in view of the construction of a regional model, the Gamma distribution could be selected for $I$, and the Weibull law for $D$ : see, e.g., the cases of Borgoforte and Pontelagoscuro in Table 4, where the actual situation already agrees with the target of a possible homogenization strategy. Clearly, this choice would not be the optimal one, but it may simplify the univariate modeling of the droughts, without too a significant loss of accuracy. Similarly, the "XClaytonClayton" copula performs well in terms of the AIC strategy: in fact, even if it is not always chosen, the corresponding values of the AIC statistics 
Table 4

List of the univariate distributions selected for the variables $I$ and $D$, for all the five river sections and the three thresholds of interest. The corresponding Monte Carlo $p$ values $p_{I}$ and $p_{D}$ are also indicated-see text.

\begin{tabular}{|c|c|c|c|}
\hline & Q275 & Q300 & Q355 \\
\hline \multicolumn{4}{|c|}{ Piacenza } \\
\hline$I$ & Weibull & Weibull & Gamma \\
\hline$p_{I}$ & 0.27 & 0.90 & 0.86 \\
\hline$D$ & GP & Weibull & GP \\
\hline$p_{D}$ & 0.76 & 0.14 & 0.85 \\
\hline \multicolumn{4}{|c|}{ Cremona } \\
\hline$I$ & Weibull & Gamma & Gamma \\
\hline$p_{I}$ & 0.53 & 0.71 & 0.95 \\
\hline$D$ & GP & LogNormal & GP \\
\hline$p_{D}$ & 0.07 & 0.26 & 0.09 \\
\hline \multicolumn{4}{|c|}{ Boretto } \\
\hline$I$ & Weibull & Gamma & Gamma \\
\hline$p_{I}$ & 0.91 & 0.77 & 0.17 \\
\hline$D$ & GP & Weibull & Weibull \\
\hline$p_{D}$ & 0.05 & 0.59 & 0.14 \\
\hline \multicolumn{4}{|c|}{ Borgoforte } \\
\hline$I$ & Gamma & Gamma & Gamma \\
\hline$p_{I}$ & 0.81 & 0.37 & 0.83 \\
\hline$D$ & Weibull & GP & Weibull \\
\hline$p_{D}$ & 0.06 & 0.30 & 0.72 \\
\hline \multicolumn{4}{|c|}{ Pontelagoscuro } \\
\hline$I$ & Gamma & Gamma & Gamma \\
\hline$p_{I}$ & 0.83 & 0.83 & 0.14 \\
\hline$D$ & Weibull & Weibull & Weibull \\
\hline$p_{D}$ & 0.32 & 0.28 & 0.42 \\
\hline
\end{tabular}

Table 5

List of the survival copulas $\widehat{\mathbf{C}}$ 's selected for all the five river sections and the three thresholds of interest. The corresponding Monte Carlo $p$-values are also indicatedsee text.

\begin{tabular}{llll}
\hline \multicolumn{2}{r}{ Q275 } & Q300 & Q355 \\
\hline $\begin{array}{llll}\text { Piacenza } \\
\widehat{\mathbf{C}}\end{array}$ & XClaytonFrank & XClaytonGumbel & XClaytonClayton \\
$p$ & 0.61 & 0.95 & 0.19 \\
Cremona & & & \\
$\widehat{\mathbf{C}}$ & XClaytonClayton & XClaytonClayton & XGumbelFrank \\
$p$ & 0.98 & 0.99 & 0.90 \\
Boretto & & & \\
$\widehat{\mathbf{C}}$ & XClaytonFrank & XClaytonClayton & XClaytonClayton \\
$p$ & 0.91 & 0.57 & 0.66 \\
Borgoforte & & & \\
$\widehat{\mathbf{C}}$ & XClaytonFrank & XClaytonGumbel & XClaytonClayton \\
$p$ & 0.96 & 0.68 & 0.75 \\
Pontelagoscuro & & \\
$\widehat{\mathbf{C}}$ & XFrankFrank & XClaytonFrank & XClaytonClayton \\
$p$ & 0.99 & 0.78 & 0.61 \\
\hline
\end{tabular}

are close to the ones computed for the copulas eventually selected. Thus, the "XClaytonClayton" model could be adopted as a general dependence structure for the river sections investigated here. However, in the following we shall not pursue any regionalization strategy, which is left for future works.

A final point that is worth stressing is as follows: the KhoudrajiLiebscher extra-parametrized copulas are always preferred among the twelve dependence structures listed in Table 3 . These copulas have the largest number of parameters (four), and hence are the most "penalized" by the corrected AIC selection procedure adopted here. Thus, the fact this family of copulas is always chosen to model the drought bivariate behavior, despite the large number of parameters, may indicate that its fitting ability (as expressed in terms of the likelihood) justify the use of additional parameters, with respect to the other 1- or 3-parameters copulas investigated.
For the sake of brevity, below we shall only illustrate the results concerning the threshold Q355, the "Emergency" one. However, similar outcomes were obtained by considering the thresholds Q275 and Q300. In addition, three historically relevant drought episodes will be considered: viz., the ones occurred in, respectively, 1943, 2003, and 2006. In particular, as stressed in De Michele et al. (2013), the 2003s event is the one showing the largest duration, and the 2006s event is the one showing the largest intensity, while the 1943s event is considered for historical reasons, being recalled as a severe drought episode managed in an emergency (war) situation. Note that the river section of Cremona is missing for the year 1943 , since no data are available. Before proceeding, we feel important to describe the structure and the content of the figures that will be presented in the sequel, as summarized below.

\subsection{The Dynamic Return Period}

In Figs. 2-4, the temporal behavior of the variables $R$ (the daily running average intensity, as in De Michele et al. (2013)) and $Z$ (the daily intensity) is presented for each river section-see the first and third columns: this gives the possibility to monitor site-by-site the "instantaneous" evolution of the drought from two different perspectives. Note that the droughts may begin on different dates at different river sections. In addition, the joint SKRP of the pair $(R, D)$ is contrasted on the same plot with the univariate RP's of the variables $R, D$, and $Z$, on a daily pace-see the second and fourth columns: this gives the possibility to appreciate the differences between the univariate and the multivariate approaches, making it evident how only the latter one can appropriately account for the joint behavior of the variables ruling the drought state. Here a GP distribution is used to model the available daily intensity observations $Z$ 's, for all river sections and thresholds: as a matter of fact, in the present work, $Z$ is not of particular interest, and it is shown for the sake of comparison only. Then, since the GP law turned out to fit reasonably well the $Z$ 's upper-tails for all the data bases considered (viz., the portion of the distribution corresponding to the largest RP's), it was used as a general fitting law, regardless of the possible peculiarities of each river section and/or threshold. Finally, in a separate panel, the R's observed at different river sections are contrasted on the same plot, in order to check the overall daily drought state in the whole basin.

\subsection{The Hazard Trajectory}

As anticipated in Section 3.3, in Figs. 5-7, a new tool is introduced for the real-time evaluation of the drought dangerousness, viz. the so-called "Hazard Trajectories". Practically, the fitting procedures discussed above yield, for each river section and threshold, suitable univariate marginals and (survival) copulas for modeling the random behavior of the pair $(I, D)$. In turn, as outlined in Salvadori et al. (2013), De Michele et al. (2013), Salvadori et al. (2014), corresponding appropriate bivariate dependence structures can be constructed, and suitable isolines with given joint SKRP can be drawn: here, six relevant multivariate RP's are chosen, i.e. $5,10,20,50,100$, and 200 years. The fundamental point is that these probability models represent the available historical information, for each river section and threshold, and may be updated as soon as new data are at disposal. Evidently, the iso-frequency curves constitute the historical knowledge at hand concerning the local drought behavior, and can be used to assess the day-by-day threatening of the episode under investigation. The Hazard Trajectory is defined as the temporal evolution path of the pair $(R$, $D$ ) as plotted over the fitted iso-frequency (i.e., iso-RP) curves: then, it is immediate to evaluate the state of a drought in terms of its joint SKRP. In turn, a real-time estimate of the drought dangerousness can be computed for each single site. Note that, for the 
sake of completeness, also the corresponding HT's of the pair $(Z, D)$ are plotted on the same graphs. However, care must be taken in interpreting the results: in fact, the isolines crossed by the $(Z, D)$ HT's are those fitted by using the average intensity data, having a distribution different from the one of $Z$. Finally, for the sake of comparison, the DRP's of the pairs $(R, D)$ 's at different river sections are contrasted on the same plot in a separate panel: this gives the possibility to monitor, in a multi-site perspective, the overall daily drought evolution in the whole basin.

\subsection{The Hazard Fan}

As anticipated in Section 3.4, Fig. 8 illustrates the concept of Hazard Fan. The idea is to introduce a prognostic tool which combines weather/drought short-term forecasts with the information supplied by the SKRP isolines discussed in Section 4.2. In the following, no real forecasts will be used: the example is purely illustrative, and constructed ad hoc, in order to show a possible practical situation; here, the drought episode occurred at Pontelagoscuro in 2006 is considered (see Figs. 4 and 7). However, should actual information be available, it would be immediate to compute real hazard scenarios, as explained below.

For illustrative purposes, suppose that the sequence of drought states $\left(I_{1}, 1\right),\left(I_{2}, 2\right), \ldots$ is known up to day 14 : in turn, the corresponding HT can be drawn in the Duration-Intensity plane, where the isolines of several SKRP's of interest are already present, as shown in Fig. 8. Now, what about the drought state (and threatening) at day 15? Let us assume that three different values of intensity are forecasted for the 15 th day (i.e., $I_{15}$ ) by exploiting the known value $I_{14}$, each with an associated probability of occurrence. In Fig. 8, the following three "virtual" scenarios $\mathcal{S}$ 's are shown:

\begin{tabular}{lll}
\hline Scenario & Intensity $I_{15}$ & Probability (\%) \\
\hline $\mathcal{S}_{1}$ & $0.8 \times I_{14}$ & 20 \\
$\mathcal{S}_{2}$ & $I_{14}$ & 30 \\
$\mathcal{S}_{3}$ & $1.2 \times I_{14}$ & 50 \\
\hline
\end{tabular}

Practically, it is assumed that the previsional models forecast a smaller intensity with $20 \%$ probability, no variation with $30 \%$ probability, and a larger intensity with $50 \%$ probability. Then, the predicted values are plotted in the Duration-Intensity plane at day 15. As a result, Fig. 8 quickly gives the possibility to realize that the drought is likely to evolve towards: $\left(\mathcal{S}_{1}\right)$ a "better" state (i.e., a SKRP of about 10 years) with $20 \%$ probability; or, $\left(\mathcal{S}_{2}\right)$ a "steady" state (i.e., a SKRP of about 20 years) with $30 \%$ probability; or, $\left(\mathcal{S}_{3}\right)$ a "worse" state (i.e., a SKRP of about 50 years) with $50 \%$ probability.

Evidently, hazard trajectories and fans, properly supported by suitable previsional models, may provide fast and valuable qualitative and quantitative indications concerning the future drought dynamics, an important piece of information for the purposes of the CR. Clearly, the procedure can be iterated and generalized, possibly considering temporal horizons longer than one single day.

\subsection{Discussion}

The analysis of Figs. 2-7 yields the following considerations.

1. As expected, the running average intensities $R$ 's are generally increasingly "ordered" following the streamflow direction (see Fig. 1), i.e. from Piacenza to Pontelagoscuro, as shown in the bottom-right panels of Figs. 2-4: occasional exceptions are due to local precipitation episodes and/or to specific rules possibly recommended by the CR for water withdrawals.
2. The first and second columns of Figs. 2-4 show an interesting comparison between the behavior of $Z$ and $R$. In general, the daily intensity $Z$ is characterized by a larger variability than the running average intensity $R$. As a matter of fact, while the former may only supply a sort of "instantaneous" picture of the drought, the latter inherits the whole phenomenological information since the very beginning of drought episode: thus, $R$ is less prone to provide biased indications about the actual state of the drought, and its evolution.

3. A few facts are evident by considering the second and fourth columns of Figs. 2-4: below we shall use the standard notation $T_{X}$ to indicate the RP of the generic variable(s)X. First, $T_{D}$ is monotonically increasing: this is obvious, since $D$ can only increase. Secondly, $T_{R}$ and $T_{Z}$ follow the daily trends of the corresponding variables (shown in the first and third columns of Figs. 2-4): this is also obvious, since these RP's are calculated via a one-to-one relationship with the univariate distributions of the variables of interest. Instead, the SKRP $T_{R D}$ of the pair $(R, D)$ appropriately describe the joint behavior of these two variables. In fact, by the end of a drought episode, $T_{R D}$ may be large even if $T_{R}$ is small, provided that $D$ is large enough (see,

e.g., the 1943s and 2003s cases in Figs. 2 and 3). Thus, the duration $D$ becomes the dominant variable if the drought episode lasts enough days: this is an important piece of information that cannot be achieved via a univariate analysis only, meaning that even small intensities may become threatening if the drought is not stopped in due time. Conversely, apparently $T_{R D}$ is dominated by the intensity variable if the drought episode is short enough, as for the 2006s cases shown in Fig. 4.

4. Occasionally, the univariate RP's of $R$ and/or $Z$ show abrupt peaks and changes, related to those of the corresponding intensity variables: see, e.g., the 2003s cases of Cremona and Boretto in Fig. 3, and all the 2006s cases in Fig. 4. Instead, the joint SKRP shows a smooth and regular behavior: thus, this latter multivariate parameter goes around the "volatility" of the univariate RP's, and keeps track of the previous states of a drought. In turn, hasty and/or improper intervention decisions may be avoided by using the multivariate approach.

5. The joint SKRP's of all the river sections, as contrasted in the bottom-right panels of Figs. 2-4, show an interesting regularity: apparently, for each episode, they follow the same daily trend over all the basin, including increasing and decreasing peaks. The different magnitudes shown at Pontelagoscuro (for the 1943s event) and at Piacenza (for the 2006s event) are simply due to the peculiarities of these two sites. In fact, Pontelagoscuro is the river section closest to the outlet of the Po river (see Fig. 1), and is generally the one most affected by drought occurrences, both in terms of intensities and durations. Instead, Piacenza meets the converse situation. The simultaneous comparison of all the DRP's provides very useful information to the CR for the purposes of drought assessment, since it is possible to monitor in real-time the evolution of the episode over all the basin. As a general comment, the issue of "Multi-site Analysis" of droughts is an important one, since droughts are spatial events affecting portions (more or less large) of a territory, and a num-ber of sub-basins. As stressed by the CR (AA. VV., 2011), the case of the Po river is particularly complex, essentially due to the strong anthropization and the variety of uses embraced: as a matter of fact, the management of a drought affecting the whole Po basin involves a large number of "compromises" between dif-ferent, and conflicting, interests. The multi-site comparison presented here may provide the $C R$ with a novel way to look at a drought evolution. However, a thorough exploration of the correlation/dependence between various gauge stations (like, e.g., the ones concerning extreme 
Table 6

Recovery time (in days) for all the five river sections, and the three drought episodes considered in this work-see text.

\begin{tabular}{lrll}
\hline Station & 1943 & 2003 & 2006 \\
\hline Piacenza & 104 & 134 & 111 \\
Cremona & - & 142 & 110 \\
Boretto & 96 & 151 & 109 \\
Borgoforte & 99 & 152 & 112 \\
Pontelagoscuro & 120 & 153 & 116 \\
\hline
\end{tabular}

floods presented in Salvadori and De Michele (2010), Durante and Salvadori (2010), and the use of multivariate 3-dimensional measures of association as in Salvadori and De Michele (2011)) is beyond the scope of this work, also considering the fact that the Authors have no access to the information needed to carry out a sensible analysis: viz., the uses of water, the rules for water withdrawals, the interventions decided by the $\mathrm{CR}$, and so on.

6. The HT's of the pair $(R, D)$ plotted in Figs. 5-7 represent a new significant tool made available to the $C R$ in order to survey the local drought threatening: in fact, they show the real-time (multivariate) state of a drought in terms of RP's, and hence are easy to read and interpret. As already mentioned, the isolines shown in the plots can be regarded as a summary of the historical information available to the CR: a clear picture of a drought state can be immediately drawn by checking the dayby-day evolution of a trajectory, and appropriate interventions may be decided in real-time by exploiting suitable prognostic models and the HF's.

A final notion of interest is represented by the "Recovery Time" (hereinafter, $R T$ ) computed in terms of the running average: practically, the RT is the length of the period, since the beginning of the drought episode, necessary for the running average to take on the value zero. From a hydrological point of view, the RT indicates how long does it take for the basin to "balance" the deficit generated by the drought considered. The RT's for all the five river sections, and the three drought episodes considered in this work, are reported in Table 6. Apparently, an interesting piece of information can be drawn by analyzing the results: viz., for a given event, the RT's are of the same magnitude for all the five sites. A posteriori, this may indicate that the river sections considered here have recov-ered the status attained before the beginning of the drought at about the same time.

\section{Conclusions}

The methodological work presented in this paper was motivated by three main considerations: (1) droughts are spatially extended phenomena; (2) several are the variables that may play a significant role in ruling the evolution of a drought; (3) droughts are characterized by a slow temporal dynamics, ranging from weeks to months (a fact usually not adequately addressed in literature). The first two considerations strongly suggest the use of multi-dimensional tools for the characterization of droughts, while the third one indicates the possibility to follow in real-time the drought evolution and its hazard status.

This paper outlines a multivariate, multi-site, frequency analysis of hydrological droughts. In particular, a drought is treated as a multivariate event, and its co-occurrence and co-evolution at different river sections is investigated. As a case study, the main river channel of the strategic Po basin (Northern Italy), sampled at five different river sections, is considered.

The multivariate statistical framework provided by the Theory of Copulas is exploited, and four valuable tools are used: namely, the joint Survival Kendall's Return Period, the Dynamic Return
Period, and the new concepts of Hazard Trajectory and Fans. As a result, the occurrence and the time evolution of droughts are described within a coherent, consistent, and organic frame with respect to other univariate, or local (single site), analyses available in literature. In turn, the procedures outlined in this paper can be used by the river Authorities for planning more effective real-time interventions to mitigate the consequences of low flows.

\section{Acknowledgements}

Helpful discussions with C. Sempi (Università del Salento, Italy) and F. Durante (Free University of Bozen-Bolzano, Italy) are acknowledged. The support of the CMCC-Centro Euro-Mediterraneo sui Cambiamenti Climatici-Lecce (Italy) is acknowledged.

\section{References}

AA. VV., 2011. Le magre del Po. Conoscerle per prevederle, cooperare per prevenirle. Fondazione CIMA, Parma, Italy. <www.cimafoundation.org> (in Italian).

Beran, M., Rodier, J., 1985. Hydrological Aspects of Drought: A Contribution to the International Hydrological Programme. Studies and Reports in Hydrology, vol. 39. Unesco-WMO, Paris, France.

Burnham, K.P., Anderson, D.R., 2002. Model Selection and Multimodel Inference: A Practical Information-Theoretic Approach, second ed. Springer-Verlag.

Byzedi, M., 2010. Analysis of hydrological drought based on daily flow series. In: Proceedings of World Academy of Science, Engineering and Technology, vol. 70 pp. 249-252.

Byzedi, M., Saghafian, B., 2009. Regional analysis of streamflow drought: a case study for southwestern Iran. In: Proceedings of World Academy of Science, Engineering and Technology, vol. 57, pp. 447-451.

Chen, L., Singh, V.P., Guo, S., Mishra, A.K., Guo, J., 2013. Drought analysis using copulas. J. Hydrol. Eng. 18 (7), 797-808.

Claeskens, G., Hjort, N., 2008. Model Selection and Model Averaging. Cambridge Series in Statistical and Probabilistic Mathematics. Cambridge University Press.

Clausen, B., Pearson, C., 1995. Regional frequency analysis of annual maximum streamflow drought. J. Hydrol. 173, 111-130.

Clausen, B., Pearson, C., 1998. Susceptibility of water supply reservoirs to drought conditions. J. Hydrol. Eng. 3 (2), 140-148.

Davison, A.C., Hinkley, D.V., 1997. Bootstrap Methods and Their Application Cambridge Series on Statistical and Probabilistic Mathematics. Cambridge University Press, Cambridge, UK.

De Michele, C., Salvadori, G., 2003. A generalized Pareto intensity-duration model of storm rainfall exploiting 2-copulas. J. Geophys. Res. 108 (D2) 4067.

De Michele, C., Salvadori, G., Vezzoli, R., Pecora, S., 2013. Multivariate assessment of droughts: frequency analysis and dynamic return period. Water Resources Res.

49 (10), 6985-6994.

Demuth, S., Heinrich, B., 1997. Temporal and spatial behaviour of droughts in south Germany. In: Gustard, A., Blazkova, S., Brilly, M., Demuth, S., Dixon, J., van Lanen, H., Llasat, C., Mikhandi, S., Servat, E. (Eds.), FRIEND’97-Regional Hydrology: Concepts and Models for Sustainable Water Resources Management (Proceedings of the Postojna, Slovenia, Conference, September-October 1997), vol. 246. IAHS, pp. 151-157.

Demuth, S., Külls, C., 1997. Probability analysis and regional aspects of droughts in southern Germany. In: Rosbjerg, D., Boutayeb, N.-E., Gustard, A., Kundzewicz, Z., Rasmussen, P. (Eds.), Sustainability of Water Resources under Increasing Uncertainty (Proceedings of Rabat Symposium SI, April 1997), vol. 240. IAHS pp. 97-104.

Dracup, J., Lee, K., Paulson, E.J., 1980a. On the definition of droughts. Water Resources Res. 16 (2), 297-302.

Dracup, J., Lee, K., Paulson, E.J., 1980b. On the statistical characteristics of drought events. Water Resources Res. 16 (2), 289-296.

Durante, F., Salvadori, G., 2010. On the construction of multivariate extreme value models via copulas. Environmetrics 21 (2), 143-161.

Engeland, K., Hisdal, H., Frigessi, A., 2004. Practical extreme value modelling of hydrological floods and droughts: a case study. Extremes 7, 5-30.

Fleig, A., Tallaksen, L., Hisdal, H., Demuth, S., 2006. A global evaluation of streamflow drought characteristics. Hydrol. Earth Syst. Sci. 10 (4), 535-552.

Ganguli, P., Reddy, M.J., 2012. Risk assessment of droughts in Gujarat using bivariate copulas. Water Resources Manage. 26 (11), 3301-3327.

Ganguli, P., Reddy, M.J., 2014. Evaluation of trends and multivariate frequency analysis of droughts in three meteorological subdivisions of Western India. Int. J. Climatol. 34, 911-928.

Gannon, J., 1964. Definition of river drought flow characteristics. Int. Assoc. Sci. Hydrol. Publ. 3, 137-150.

Genest, C., Rémillard, B., Beaudoin, D., 2009. Goodness-of-fit tests for copulas: a review and a power study. Insur.: Math. Econ. 44, 199-213.

Gräler, B., van den Berg, M.J., Vandenberghe, S., Petroselli, A., Grimaldi, S., Baets, B.D. Verhoest, N.E.C., 2013. Multivariate return periods in hydrology: a critical and practical review focusing on synthetic design hydrograph estimation. Hydrol. Earth Syst. Sci. 17, 1281-1296. 
Gumbel, E., 1963. Statistical forecast of droughts. Bull. Int. Assoc. Sci. Hydrol. 8 (1), $5-23$.

Kao, S., Govindaraju, R., 2010. A copula-based joint deficit index for droughts. J. Hydrol. 380, 121-134.

Kjeldsen, T., Lundorf, A., Rosbjerg, D., 2000. Use of a two-component exponential distribution in partial duration modelling of hydrological droughts in Zimbabwean rivers. Hydrol. Sci. J. 45 (2), 285-298.

McKee, T., Doesken, N., Kleist, J., 1993. The relationship of droughts frequency and duration to time scales. In: Proceedings of the 8th Conference on Applied Climatology. pp. 17-22.

Mirabbasi, R., Fakheri-Fard, A., Dinpashoh, Y., 2012. Bivariate drought frequency analysis using the copula method. Theor. Appl. Climatol. 108 (1-2), 191-206.

Mishra, A., Singh, V., 2010. A review of drought concepts. J. Hydrol. 391, 202-216.

Mishra, A.K., Singh, V.P., 2011. Drought modeling - a review. J. Hydrol. 403 (1-2), $157-175$.

Nelsen, R.B., 2006. An Introduction to Copulas, second ed. Springer-Verlag, New York.

Palmer, W., 1965. Meteorological Drought. Tech. Rep., Dept. of Commerce, Weather Bureau.

Reddy, M.J., Ganguli, P., 2012. Application of copulas for derivation of drought severity-duration-frequency curves. Hydrol. Process. 26 (11), 1672-1685.

Salvadori, G., De Michele, C., 2010. Multivariate multiparameter extreme value models and return periods: a copula approach. Water Resources Res. 46, W10501. http://dx.doi.org/10.1029/2009WR009040.

Salvadori, G., De Michele, C., 2011. Estimating strategies for multiparameter multivariate extreme value copulas. Hydrol. Earth Syst. Sci. 15, 141-150. http://dx.doi.org/10.5194/hess-15-141-2011.

Salvadori, G., DeMichele, C., Kottegoda, N., Rosso, R., Nature, Extremes in, 2007. An Approach using Copulas. Water Science and Technology Library Series, vol. 56. Springer, Dordrecht, iSBN: 978-1-4020-4415-1.

Salvadori, G., Durante, F., De Michele, C., 2013. Multivariate return period calculation via survival functions. Water Resources Res. 49, 2308-2311. Salvadori, G., Tomasicchio, G.R., D’Alessandro, F., 2014. Practical guidelines for multivariate analysis and design in coastal and off-shore engineering. Coast. Eng. 88, 1-14. http://dx.doi.org/10.1016/j.coastaleng.2014.01.011.

Sen, Z., 1977. Run-sums of annual flow series. J. Hydrol. 35 (3-4), 311-324.
Serinaldi, F., Bonaccorso, B., Cancelliere, A., Grimaldi, S., 2009. Probabilistic characterization of drought properties through copulas. Phys. Chem. Earth 34 (10-12), 596-605.

Shiau, J.T., 2006. Fitting drought duration and severity with two-dimensional copulas. Water Resources Manage 20 (5), 795-815.

Shiau, J.T., Modarres, R., 2009. Copula-based drought severity-duration-frequency analysis in Iran. Meteorol. Appl. 16 (4), 481-489.

Song, S.-B., Kang, Y., 2011. Pair-copula decomposition constructions for multivariate hydrological drought frequency analysis. In: Proc. 2011 International Symposium on Water Resource and Environmental Protection (ISWREP), vol. 4. pp. 2635-2638.

Song, S., Singh, V.P., 2010. Frequency analysis of droughts using the Plackett copula and parameter estimation by genetic algorithm. Stoch. Env. Res. Risk Assess. 24 (5), 783-805.

Tallaksen, L., Madsen, H., Clausen, B., 1997. On the definition and modelling of streamflow drought duration and deficit volume. Hydrol. Sci. J. 42 (1), 15-33. The European Parliament and The Council, 6.11.2007. Directive 2007/60/EC: On the Assessment and Management of Flood Risks. Official Journal of the European Union.

Turco, M., Vezzoli, R., Da Ronco, P., Mercogliano, P., 2013. Variation in Discharge, Precipitation and Temperature in Po River and Tributaries Basins. CMCC Research Paper 0185, Centro Euro-Mediterraneo sui Cambiamenti Climatici, Italy.

Wilhite, D., Glantz, M., 1987. Understanding the drought phenomenon: the role of definitions. In: Wilhite, D., Easterling, W., Wood, D. (Eds.), Planning for Drought: Toward a Reduction of Societal Vulnerability. Westview Press, USA, pp. 111-120.

Wong, G., Lambert, M., Leonard, M., Metcalfe, A.V., 2010. Drought analysis using trivariate copulas conditional on climatic states. ASCE - J. Hydrol. Eng. 15 (2), 129-141.

Yevjevich, V., 1967. An Objective Approach to Definitions and Investigations of Continental Hydrologic Droughts. Hydrologic Paper 23, Colorado State University, Fort Collins.

Zelenhasić, E., Salvai, A., 1987. A method of streamflow drought analysis. Water Resources Res. 23 (1), 156-168. 